\title{
Measuring Technology Differences Across Football Manufacturers in Sialkot
}

\section{Tariq Raza*}

\begin{abstract}
A fascinating example of the fluctuating fortunes of Pakistani exports is that of the footballs produced by a cluster of manufacturers in Sialkot. Dominated by Pakistani firms, the sector is now under heavy threat from cheaper balls produced in East Asia (particularly China). What is striking is that the technology used by most firms has not progressed significantly in the last 30 years. This raises the question of whether Pakistan is falling behind the technology frontier. Using data from a sample of firms, we map the football production process and focus on different cutting technologies to compare productivity across firms and measure the benefits of upgrading this technology across firms of different sizes. Our results show that technology upgrading comes at a cost, but is worthwhile for firms that need to produce a large volume of balls. However, the falling demand for Pakistani balls may not justify this for most small and medium firms in the sector, which make up the vast majority of firms in the cluster.
\end{abstract}

Keywords: Technology, manufacturers, footballs, Sialkot, Pakistan.

JEL classification: $\mathrm{O} 33$.

\section{Introduction}

The city of Sialkot is the center of football manufacturing in Pakistan. The origins of this industry, which is currently home to a large number of football firms, dates back to British colonial rule in the Subcontinent. Over the years, the football industry of this region, which now constitutes both large and small production units, has experienced considerable growth. However, in the last 15 years, Pakistan has lost a significant portion of the world's market share to China, which to date continues to pose a threat to the domestic industry (see Atkin et al., 2015b, figure A.1).

\footnotetext{
* Lahore School of Economics, Pakistan.

We are grateful to our team at the Technology Management Centre, Lahore School of Economics, for generous research support, in particular Azam Chaudhry, Theresa Chaudhry, Mahwish Faran and Saba Fazal; Farhat Afshan for her excellent research assistance; Umair Ayaz for his valuable inputs; and Rajah Rasiah, Inayat Ullah Mangla, Irfan ul Haque for their helpful comments. All errors are our own.
} 
This paper maps the football manufacturing process and looks at the technology used at each stage of production. It then focuses on the technologies used to cut the pieces used to make footballs, which we find to be the main bottleneck in the production process if the firm is operating near full capacity. Comparing technologies, we find that, while the higher cutting technology is indeed more productive in terms of labor output, the scale of production in most firms does not justify the investment. We also present some theories as to why firms that should upgrade their technology, do not.

\section{The Handstitched Football Production Process}

The production of footballs in the Sialkot area dates back to the late 18th century when two Sikh brothers began producing footballs. The original football manufacturers were leather makers who took the skills they had gained from producing for the Mughals and then the British to start stitching footballs. Most of these footballs were made for British troops in India, the UK and British territories (see Atkin et al., in press).

While the original football manufacturing process used leather, the current production process relies on faux leather or rexine. The steps followed by the present manufacturers mirror the production process from more than a century ago (see Atkin et al., 2015a):

- Cutting out rectangular rexine sheets from long rolls of rexine.

- Gluing layers of cloth to the back of the rexine sheets, using an imported rubber-based glue. This adds bounciness to the balls and the cloth adds weight and durability (multiple layers, usually cotton or polyester or a combination of both, can be added, depending on the quality of the ball).

- Cutting out the pieces of rexine that go into the production of the ball. The majority of balls produced are 'buckyballs', which require 20 hexagonal pieces and 12 pentagonal pieces.

- Printing designs and logos onto the hexagons and pentagons, based on customer preferences and using durable ink or paint.

- Stitching these pieces together to make the ball (a rubber bladder is glued onto one piece and this piece is stitched to the other pieces).

- Checking the balls for quality and durability; cleaning and packing the balls for shipping. 
Each production step requires different labor skills and, in some cases, different technologies. Almost all firms cut and layer the rexine with cloth manually, though one of the largest firms in the industry uses an automatic machine for lamination. The cutting process involves either cutting dies (which are rather like cookie cutters) combined with manual presses or a large hydraulic press that cuts out half or a full sheet of pieces automatically.

Similarly, while most firms in Sialkot employ labor to hand-stitch the balls, a growing number of firms have begun using stitching machines (similar to sewing machines). The higher-quality balls are hand-stitched; the lower-quality balls (called 'promotional balls') are machine-stitched. A few firms use a more advanced technique known as 'thermo-layering', in which the pieces are molded onto bladders using heat-based technology. The majority of firms print designs and logos on the balls manually and the same applies to the final quality checks, cleaning and packing.

By our definition, an operational football firm must have an inhouse cutting facility, otherwise it serves more as a trader than a producer. Each step employs people who are usually hired on contract (a common practice) and are typically paid per piece (piece rates). The football panels are then sent elsewhere to be stitched - usually to stitching centers situated in villages on the outskirts of Sialkot.

\section{Reasons for Focusing on Cutting Technologies}

Our research team observed the machines used to cut the primary raw material (laminated synthetic leather sheets) into panels. The findings allowed us to determine the parameters needed to compute the output capacity of each machine. As mentioned earlier, football manufacturing has four key production steps: lamination, cutting, printing and stitching.

One of the largest firms in the industry, which uses an automatic machine for lamination, pointed out that its daily output of rexine sheets laminated exceeded the number of sheets cut daily by all the in-house cutting technologies. Two other medium firms said that, in the absence of financial constraints and a regular supply of football orders, the cutting machines' output capacity could become a firm's production frontier. This gives us sufficient reason to assume that the output of all the cutting technologies owned by a firm can represent its production frontier. Thus, under the most efficient circumstances, the output of its cutting technologies marks a firm's production limits. 


\section{A General Model for the Cutting Capacity of a Firm}

This section develops a general model to capture the maximum output capacity of a cutting technology, $\theta$, used to produce footballs. A football is made up of a combination of different panels. Let the total number of panels in one ball be denoted by $\gamma$ and each panel type by $i$.

$$
\gamma=\sum_{i=1}^{k} \chi_{i}
$$

where $k$ is the number of panel types in a football and $\chi_{i}$ is the number of pieces of type $i$ panels needed to produce a single football.

$T$ represents the total time spent cutting laminated rexine sheets:

$$
T=\sum_{i=1}^{k} T_{i}
$$

where $T_{i}$ is the total time spent cutting out panels of type $i$ from the laminated rexine sheets. Equation (2) implies that the total time spent cutting rexine sheets is the sum of time spent cutting rexine sheets for each panel type $i$.

$$
\begin{aligned}
& \text { Writing } T_{i}=t_{i}^{\theta} \cdot N_{i} \text { and substituting it into Equation (2) gives us } \\
& T=\sum_{i=1}^{k} t_{i}^{\theta} \cdot N_{i}
\end{aligned}
$$

where $t_{i}^{\theta}$ is the time taken to cut a single rexine sheet to obtain type $i$ panels using technology $\theta$ and $N_{i}$ is the total number of sheets cut for type $i$ panels.

$$
B_{i}=\frac{\eta_{i}^{\theta} \cdot N_{i}}{\chi_{i}}
$$

Here, $B_{i}$ is the number of footballs producible, given the number of type $i$ panels available. $\eta_{i}^{\theta}$ is the number of type $i$ panels obtained from a single rexine sheet, using technology $\theta$. The numerator indicates the total number of type $i$ panels.

Conditional on the following,

$$
B_{i}=B_{j} \forall i, j=1 \text { to } k \text { and } i \neq j
$$

and 


$$
\frac{\eta_{i}^{\theta} \cdot N_{i}}{\chi_{i}}=\frac{\eta_{j}^{\theta} \cdot N_{j}}{\chi_{j}}
$$

and using Equation (3), we calculate,

$$
N_{i}^{*}=\frac{T}{t_{i}^{\theta}+\sum_{j=1}^{k} \frac{\chi_{j}}{\chi_{i}} \cdot \frac{\eta_{i}^{\theta}}{\eta_{j}^{\theta}} \cdot t_{j}^{\theta}}
$$

where $N_{i}^{*}$ is a $f\left(T, \chi_{i, j}, \eta_{i, j}, t_{i, j}, \theta\right)$ and $i \neq j$. Using the equation below, we can calculate the number of footballs that can be produced in time $T$ using technology $\theta$.

$$
B_{i, j}^{\theta}=\frac{\eta_{i, j}^{\theta} \cdot N_{i, j}^{*}}{\chi_{i, j}} \forall i, j=1 \text { to } k \text { and } i \neq j
$$

This model can be used to estimate:

- The production capacity of a cutting technology meant for any kind of ball

- The number of sheets required to complete an order

- Given the output (the footballs), the number of rexine sheets required for each panel type $i$.

To focus on what we consider the most interesting case in the industry, we will apply the model to determine the production capacity of the cutting technologies generally used in Sialkot's football industry to produce the most common ball: a 32-panel, size 5 football. We also impose the following parameter: the edge-length of the panel size is $43.75 \mathrm{~mm}$.

As mentioned previously, the 32-panel football is a combination of two types of panels: hexagons (denoted by $H$ ) and pentagons (denoted by $P)$. Thus, we have:

$$
\begin{aligned}
& \gamma=\chi_{H}+\chi_{H} \\
& T=t^{\theta}{ }_{H} \cdot N_{H}+t_{P}^{\theta} \cdot N_{P}
\end{aligned}
$$


Conditional on the following,

$$
B_{H}=B_{P}
$$

we get

$$
N_{H}=\frac{\chi_{H}}{\chi_{P}} \cdot \frac{\eta_{P}^{\theta}}{\eta_{H}^{\theta}} \cdot N_{P}
$$

Using Equations (b) and (d), we calculate:

$$
\begin{aligned}
& N_{H}{ }^{*}=\frac{T}{t_{H}{ }^{\theta}+\frac{\chi_{P}}{\chi_{H}} \cdot \frac{\eta_{H}{ }^{\theta}}{\eta_{P}{ }^{\theta}} \cdot t_{P}{ }^{\theta}} \\
& N_{P}^{*}=\frac{T}{t_{P}{ }^{\theta}+\frac{\chi_{H}}{\chi_{P}} \cdot \frac{\eta_{P}{ }^{\theta}}{\eta_{H}{ }^{\theta}} \cdot t_{H}{ }^{\theta}} \\
& B_{H, P}^{\theta}=\frac{\eta_{H, P}^{\theta} \cdot N_{H, P}^{*}}{\chi_{H, P}}
\end{aligned}
$$

where the following are predetermined:

- The total number of pieces per football, $\gamma=32$

- The number of panel types, $k=2$

- Panel types $i=$ hexagon $(H)$ and pentagon $(P)$

- The number of hexagonal pieces in each football, $\chi_{H}=20$

- The number of pentagonal pieces in each football, $\chi_{P}=12$.

\section{Various Cutting Technologies}

We now turn to the machine types used, $\theta$. This includes specific technologies being used in Sialkot's football industry that play a critical role in cutting laminated rexine sheets into the panels necessary for football production. 
The most commonly used machine is the locally manufactured manual press. This particular technology enables firms to cut out panels with the help of a single skilled cutter. The cutting expert adjusts the rexine sheet appropriately under the press while manually holding the metal die in position over the sheet. He then pushes down on a pedal, which sets the press into motion, hitting the metal die that allows it to come sharply down onto the sheet, cutting out the intended panels. The cutter then moves the sheet along the machine, while working the pedal continuously.

The metal die can be any shape. In the case of football production, the most common die comes in a hexagon/pentagon shape and is back-toback. Going forward, we refer to the double-panel die combined with a manual press as DP-MP. The die cuts out two panels with each stroke of the press. Prior to the double-panel die, the industry used a single-panel die, also in the shape of a hexagon/pentagon. This die cuts out a single piece (either a hexagon or pentagon) from the laminated rexine sheet with each stroke of the manual press. It is still used, but rarely. Hereafter, we refer to this technology as SP-MP.

The larger firms in the industry also use a table cutting (TC) press. Unlike the wheel manual press, this particular technology requires minimal manual intervention. The metal dies are already fixed on the hydraulic press: when the machine is turned on, they descend gradually onto the rexine sheet, cutting out the panels. The only time that human aid is required is when the rexine sheet needs to be spread out on a solid flat surface under the cutting press and when it is finally pulled out after having been cut. Table cutting presses can be used with dies that cut half a rexine sheet (TC-HS) or an entire rexine sheet (TC-FS) with each stroke. Relative to the manual press, this is a faster process, allowing more panels to be cut out in a given period of time.

One of the most technologically advanced cutting processes is the click-press process, which is common internationally. The click press is more mechanized, which means that the machine is operated by clicking two buttons simultaneously. This is far easier and quieter than any of the other processes.

\section{Comparing Output Across Cutting Technologies}

Since the firm's production capacity is limited by its cutting capacity when it is operating at full potential, this section looks at the differences in potential output among the different technologies we have 
observed. As Table 1 shows, the SP-MP, which is among the oldest technologies, yields about 600 balls a day. At the next level up, the newer DP-MP can cut almost double that amount.

Table 1: Maximum daily output, by technology

\begin{tabular}{lc}
\hline Cutting technology & Maximum daily output \\
\hline Single-panel manual press* & 600 \\
Click press $^{*}$ & 413 \\
Double-panel manual press** $^{* *}$ & 1,109 \\
Table-cutting half-sheet** $^{*}$ & 2,423 \\
\hline
\end{tabular}

Note: ${ }^{*}=$ calculated using firm-level data, ${ }^{* *}=$ calculated using our model.

Source: Authors' calculations based on survey results.

Moving up the technology ladder to the TC-HS process, we see that one machine can cut almost 2,500 balls a day, which is four times the output of the simple SP-MP and more than double the output of the DP$\mathrm{MP}$. The technologically more advanced click press is the least productive in terms of the number of balls produced, but is used by firms to comply with certain labor standards and certification issues since it requires the least physical effort and is the quietest technology.

At face value, it would seem that moving from the SP-MP to the DP-MP to the TC-HS process is an easy decision. However, while the single-panel and double-panel manual presses both require a single worker (working a six-hour shift), the half-sheet cutting press needs two workers. Table 2 presents the maximum daily output per worker. Again, the DP-MP and TC-HS processes produce far more balls per worker than the other technologies. Since these are the two most prevalent cutting technologies in Sialkot, the numbers agree with the reality on the ground.

\section{Table 2: Maximum daily output per worker, by technology}

\begin{tabular}{lc}
\hline Cutting technology & Maximum daily output per worker \\
\hline Single-panel manual press & 600 \\
Click press & 413 \\
Double-panel manual press & 1,109 \\
Table-cutting half-sheet & 1,212 \\
\hline
\end{tabular}

Source: Authors' calculations based on survey results. 
Tables 3 and 4 convert the daily output to monthly numbers. This is where the story is more revealing. Most firms use DP-MP even though the output of the half-sheet hydraulic press is far higher. We ask why firms do not simply adopt the latter. Are they acting irrationally?

Table 3: Maximum monthly output, by technology

\begin{tabular}{lc}
\hline Cutting technology & Maximum monthly output \\
\hline Single-panel manual press & 15,000 \\
Click press & 10,325 \\
Double-panel manual press & 27,725 \\
Table-cutting half-sheet & 60,600 \\
\hline
\end{tabular}

Source: Authors' calculations based on survey results.

Table 4: Maximum monthly output per worker, by technology

\begin{tabular}{lc}
\hline Cutting technology & Maximum monthly output per worker \\
\hline Single-panel manual press & 15,000 \\
Click press & 10,325 \\
Double-panel manual press & 27,725 \\
Table-cutting half-sheet & 30,300 \\
\hline
\end{tabular}

Source: Authors' calculations based on survey results.

\section{Comparison of Cutting Costs: DP-MP versus TC-HS}

Up till now, the story of football production in Sialkot has been simple: firms laminate and cut out pieces from rexine sheets; these are printed and stitched together. The binding constraint to production in the football sector seems to be the number of pieces that can be cut out of the rexine sheets (given the firm is operating at its full potential). Additionally, various technologies are used in the cutting process. As one moves up the technology ladder, these produce more balls (the click press is an exception, but the reason for using it is explained above).

The two technologies we observed that produce the most output per worker are the DP-MP and TC-HS technologies. Since the latter produces more balls per worker, the question that arises is why all firms do not shift from the former to the latter. One potential reason could be that factoring labor costs into the equation makes the half-sheet hydraulic press less attractive. To test this idea, we asked four football manufacturers to tell us their labor costs associated with using the DP-MP 
technology. One of these firms also uses the TC-HS technology and reported the labor costs associated with it.

Table 5 shows the labor costs for both technologies. What is interesting is that one firm (which uses both technologies) pays the workers who operate the half-sheet table cutting machine a monthly salary, but all the firms (including the 'large' firm) pay cutters using the DP-MP technology a piece rate.

Table 5: Labor cost, by technology

\begin{tabular}{lcc}
\hline Firm type & $\begin{array}{c}\text { Labor cost of cutting (based } \\
\text { on piece rate), using DP-MP }\end{array}$ & $\begin{array}{c}\text { Labor cost of cutting, using } \\
\text { TC-HS }\end{array}$ \\
\hline Per ball (PRs) & Per month (PRs) \\
\hline Medium-small & 2.00 & \\
Small-medium & 3.00 & \\
Medium-large & 1.75 & 14,000 \\
Large & 1.20 & \\
\hline
\end{tabular}

Note: Firms are categorized by average monthly output.

Source: Authors' calculations based on survey results.

Table 6 converts the monthly salaries of the workers operating the half-sheet hydraulic press into per-ball costs (assuming the firm produces close to its maximum production capacity). Here, we see that the labor cost per ball using the more advanced technology is less than half the labor cost per ball of the older DP-MP technology. Again, this begs the question of why firms are not upgrading their technology. In the next section, we provide some hypotheses. It is also interesting to note that, relative to the others, the 'large' firm has been able to bid down the cutting cost per ball using DP-MP.

Table 6: Labor cost per ball, by technology

\begin{tabular}{lcc}
\hline Firm type & $\begin{array}{c}\text { Labor cost of cutting (based } \\
\text { on piece rate), using DP-MP }\end{array}$ & $\begin{array}{c}\text { Labor cost of cutting, } \\
\text { using TC-HS }\end{array}$ \\
\hline & Per ball (PRs) & Per ball (PRs) \\
\hline Small & 2.00 & \\
Medium-small & 3.00 & \\
Small-medium & 1.75 & \\
Medium-large & 1.20 & 0.46 \\
Large & 1.10 & \\
\hline
\end{tabular}

Source: Authors' calculations based on survey results. 


\section{Why Aren't All Firms Switching from MP to TC Technology?}

In the previous sections, we saw that the higher technology produces more balls per month and more balls per worker per month. It is also cheaper in terms of labor costs per worker (assuming workers are paid a fixed rate). Below, we hypothesize why firms are not upgrading their technology.

\subsection{Cost}

A key difference between the technologies (other than output and productivity) is their cost. Table 7 shows that there is a significant difference in cost between the older technology and the newer technology, which may hinder small and medium firms from adopting the latter.

Table 7: Cost of technology

\begin{tabular}{lccc}
\hline Technology & Labor & Price of new machine & $\begin{array}{c}\text { Annual repair and } \\
\text { maintenance (av.) }\end{array}$ \\
\hline & & PRs & PRs \\
\hline DP-MP & 1 & 150,000 & 16,000 \\
TC-HS & 2 & 400,000 & 100,000 \\
\hline
\end{tabular}

Source: Authors' calculations based on survey results.

\subsection{Operating Capacity}

The second issue concerns scale. Are firms producing at levels that would justify the cost of the more advanced technology? Table 8 gives an interesting breakdown of output for five firms of varying size. We then calculate their maximum monthly output potential using the earlier equation $\left(Y_{c}\right)$. The firms also reported their estimated maximum monthly capacity $(Y p)$. Next, we give the reported average monthly output of balls produced by each firm $(Y a)$. Finally, we calculate a capacity utilization number that indicates the amount a firm is producing as a percentage of total output $\left(Y_{a} / Y_{c}\right)$. 
Table 8: Output, by technology and firm type

\begin{tabular}{lccccccc}
\hline Firm type $^{*}$ & Code & DP-MP & TC-HS & \multicolumn{1}{c}{$\boldsymbol{c}$} & \multicolumn{1}{c}{$\boldsymbol{p}$} & \multicolumn{1}{c}{$\boldsymbol{\boldsymbol { a }}$} & $\boldsymbol{Y \boldsymbol { a } / \boldsymbol { Y } \boldsymbol { c }}$ \\
\hline Small & $\mathrm{S}$ & 1 & 0 & 27,725 & 25,000 & 2,000 & 7.2 \\
Medium-small & $\mathrm{MS}$ & 1 & 0 & 27,725 & 20,000 & 2,400 & 8.7 \\
Small-medium & $\mathrm{SM}$ & 2 & 0 & 55,450 & 30,000 & 7,500 & 13.5 \\
Medium-large & $\mathrm{ML}$ & 14 & 0 & 388,150 & 375,000 & 125,000 & 32.2 \\
Large & $\mathrm{L}$ & 4 & 4 & 353,200 & 350,000 & 291,667 & 82.6 \\
\hline
\end{tabular}

Note: $Y_{c}=$ monthly output capacity (calculated), Yp = monthly output capacity (firm's estimate), $\mathrm{Ya}=$ monthly average output in 2015, Ya/Yc = percentage capacity utilization. * = firms using neither SP-MP nor TC-FS.

Source: Authors' calculations based on survey results.

The numbers show that the small and medium firms operate far below capacity. The largest firm is the only one operating close to full capacity. Note that one firm is using 14 DP-MPs, but has still not upgraded its technology. The lesson here is that most firms are not operating near their production capacities and do not think their scale justifies moving up the cutting-technology ladder.

\subsection{Piece Rate versus Fixed Rate}

As discussed earlier, the 'large' firm, which uses both technologies, pays workers who operate the TC-HS machine a monthly salary. By doing so, it is able to reduce the labor cost per worker. There is a significant body of literature available on high-powered incentives (such as piece rates) and low-powered incentives (such as fixed wages) and how these affect worker productivity (see Gibbons \& Roberts, 2013).

Ceteris paribus, firms that are producing near full capacity may find it costlier to implement the higher cutting technology if they operate under a piece rate system, particularly given that the machine costs more to repair and maintain each year (see Table 7). For firms with significantly large production, a major incentive to move to the higher technology would be the labor cost saving, but this may only be possible under a fixed rate system and depends heavily on how the firm designs its contracts.

\subsection{Slow Adoption of Technology}

Another issue is the inertia of existing technologies or slow adoption of new technologies. In other words, firms may be reluctant to move up the technology ladder if they are comfortable with their existing 
technology and disinclined to change. An interesting case study of this is when the double-panel die was introduced in the late 1970s. Firms found they could use their existing manual presses and purchase the new dies. This required the capital investment of switching from their current singlepanel dies (for all football sizes) to double-panel dies; it also entailed the cost of retraining their workers. Despite this, the cost savings were significant. According to estimates, ${ }^{1}$ the amount of rexine wasted fell by 20-30 percent, which led to a reduction in costs of almost 10 percent.

Table 9 shows when the sample firms were established and when they adopted the double-panel die to replace the single-panel die. The oldest firm took almost 20 years to switch despite the unambiguous benefits. The newer firms took less time, but even the largest firm, which stood to gain the most, took four years.

Table 9: Date of switching from SP to DP technology

\begin{tabular}{lccc}
\hline Firm type & Code & Tech. adopted in & Firm established in \\
\hline Medium-small & MS & 2002 & 1995 \\
Small-medium & SM & 2005 & 1984 \\
Large & L & 1991 & 1987 \\
\hline
\end{tabular}

Note: DP technology was introduced in the late 1970s.

Source: Authors' calculations based on survey results.

\subsection{Reluctance to Reduce Labor Force}

One of the important findings of this paper is that output per worker is higher for the higher-tech capital. Since firms are constrained in terms of international demand, it is very possible that those that upgrade their technology may end up reducing their workforce. Our interviews with firms show that owners are reluctant to fire workers unless the international demand for footballs were to fall drastically. This means that one reason firms - especially medium firms with constrained demand for their balls - are reluctant to upgrade their technology is that it may entail having to fire workers.

\section{Conclusion}

This paper has looked at the production process for hand-stitched footballs made in Sialkot. We began by mapping the production process

\footnotetext{
${ }^{1}$ Estimates recorded from firm interviews.
} 
and used this to determine the main bottleneck (if firms are operating near capacity): the stage at which pieces are cut out of the rexine (artificial leather) sheets. We then looked at each of the technologies used in the cutting process and used the data we had collected to compare these in terms of productivity and labor cost per unit.

Moving up the cutting technology ladder enables firms to produce higher levels of output. One advanced technology, however, is the least productive, but puts less strain on workers. When we look at the maximum daily output per worker, we find that two technologies are the most productive per worker - the DP-MP and the table-cutting process. This makes sense since these are the two most prevalent cutting technologies in Sialkot. Narrowing our focus to these two competing technologies, we see that the more advanced technology (TC-HS) is more productive in terms of labor output than the older one (DP-MP).

This raises the question of why firms are not upgrading their technology. We respond with three hypotheses. First, the significant difference in the cost of the older and newer technologies may act as a barrier to adopting the latter for small and medium firms. Second, the low scale of operation of most firms does not justify technological upgrading. In particular, since most firms are not operating near their maximum production capacity, they feel they cannot justify moving up the cutting technology ladder.

Third, a certain level of 'technological inertia' has slowed down the adoption of new technologies: firms may be reluctant to move up the technology ladder because they are comfortable with their existing technology and disinclined to change. We give the example of how firms took years to adopt the previous improvement in cutting technology even though it required minimal investment. Finally, firm owners are reluctant to fire workers, which means that firms may be reluctant to adopt new technology if they feel this will force them to have a smaller workforce. 


\section{References}

Atkin, D., Chaudhry, A., Chaudry, S., Khandelwal, A., Verhoogen, E. (in press). On the origins and development of Pakistan's soccer-ball cluster. World Bank Economic Review.

Atkin, D., Chaudhry, A., Chaudry, S., Khandelwal, A., Verhoogen, E. (2015a). Markup and cost dispersion across firms: Direct evidence from producer surveys in Pakistan. American Economic Review, 105(5), 537-544.

Atkin, D., Chaudhry, A., Chaudry, S., Khandelwal, A., Verhoogen, E. (2015b). Organizational barriers to technology adoption: Evidence from soccer-ball producers in Pakistan (Working Paper No. 21417). Cambridge, MA: National Bureau of Economic Research.

De Borger, B., \& Kerstens, K. (2000). The Malmquist productivity index and plant capacity utilization. Scandinavian Journal of Economics, 102(2), 303-310.

Färe, R., Grosskopf, S., Norris, M., \& Zhang, Z. (1994). Productivity growth, technical progress and efficiency change in industrialized countries. American Economic Review, 84(1), 66-83.

Gibbons, R., \& Roberts, J. (Eds.). (2013). The handbook of organizational economics. Princeton, NJ: Princeton University Press.

Nadvi, K. (2011). Labor standards and technological upgrading: Competitive challenges in the global football industry. International Journal of Technological Learning, Innovation and Development, 4(1-3), 235-257.

Sandal, M. I. (n.d.). History of football and Pakistan's contribution. Unpublished manuscript.

Yang, C.-H., \& Chen, K.-H. (2009). Are small firms less efficient? Small Business Economics, 32(4), 375-395. 